\title{
Air pollution monitoring and evaluation framework for South Africa: prioritizing vulnerable communities
}

\author{
C. Wright \\ CSIR Natural Resources and the Environment, \\ Environmental Health Research Group, South Africa
}

\begin{abstract}
Air pollution is a serious environmental health threat to humans. Furthermore, the severity of health outcomes associated with air pollution exposure is not uniform within populations. In South Africa, the problem is exacerbated since several vulnerable communities live in close proximity to pollution sources. The National Environmental Management: Air Quality Act No. 39 of 2004 aims to protect the health of South Africans through the implementation of air quality management plans and monitoring programmes. To assess the effectiveness of these actions and implemented mitigation measures with respect to health outcomes, specific indicators are required. Therefore, the aim was to determine South African-appropriate indicators and health data necessary to successfully evaluate efforts to reduce air pollution and associated adverse human health effects, and to consider mechanisms for accessing and integrating these data into a monitoring and evaluation framework. In a preliminary study, a population air pollution exposure and vulnerability risk prioritization model for potential use by municipal air quality managers was developed. The model included vulnerability factors such as poverty, respiratory and other diseases, lack of education and poor living conditions, all of which are important in areas occupied by previously disadvantaged communities. High-risk areas in terms of air pollution health impacts were identified using a set of indicators that assessed air pollution sources, ambient air pollution levels and air pollution potential, as well as community awareness, observations, perceptions and actions. The model was applied to the eThekwini Municipality (Kwazulu-Natal Province). Data were extracted from multiple sources for a selection of municipal wards and scored to illustrate categorisation of communities to prioritize those vulnerable
\end{abstract}


communities with excess exposure to ambient air pollution. Results were used to identify high-risk communities such that resources, funding and capacity may be appropriately allocated. Feasible and relevant indicators were then considered for the proposed monitoring and evaluation framework to reduce vulnerability and the incidence of adverse respiratory health impacts.

Keywords: air pollution, vulnerability, monitoring and evaluation.

\section{Introduction}

Air pollution exposure is a serious environmental health threat to humans, where evidence suggests that the longer the exposure, the greater the health risks, especially for cardiovascular mortality [1]. Moreover, the severity of health outcomes associated with air pollution exposure is not uniform within populations [2].

South Africa passed the National Environmental Management: Air Quality Act No. 39 of 2004 (NEM AQA) [3] to manage ambient air quality and thereby protect the health of the South African population. This legislation marks a paradigm shift in the manner in which air quality is managed in South Africa and for the first time presents an opportunity to include human health considerations.

Each South African local municipality is required to draft and implement an air quality management plan (AQMP) with the aim of maintaining ambient air quality levels below specified standards and thus minimising adverse human health impacts. To assess the effectiveness of these actions and implemented mitigation measures with respect to health outcomes, specific indicators, including vulnerability, demographic and health indicators, are required.

Both the National Department of Environmental Affairs and Tourism and the Department of Health are anxious to know whether air pollution-associated adverse health effects will be alleviated once the NEM AQA and AQMPs are put into practice. Identifying appropriate indicators and motivating for access to health data, currently extremely difficult to obtain, are important steps to realising this goal.

The aim of this paper was to describe preliminary work to define environmental health indicators as part of an air pollution monitoring and evaluation (M\&E) framework for South Africa that will assess implemented mitigation measures specific to health outcomes with particular emphasis on vulnerable communities.

\subsection{Air pollution associated health risks in South Africa}

In South Africa, the key focus areas for environmental health include, amongst others, acute respiratory tract infections such as pneumonia, and lung diseases, especially tuberculosis and asthma [4]. Excess air pollution exposure is a modifiable risk factor for these adverse human health effects. The South African Comparative Risk Assessment ranked indoor air and urban air pollution $15^{\text {th }}$ and $17^{\text {th }}$ respectively (\% total Disability Adjusted Life Years-DALYs) as risk factors causing the burden of disease. Interestingly, associated health effects, namely, 
tuberculosis and lower respiratory tract infections were ranked $3^{\text {rd }}$ and $6^{\text {th }}$ respectively (\% total DALYs) in terms of disease prevalence [5].

\subsection{Population air pollution exposure and vulnerability risk assessment}

Vulnerability may be defined as the "interface between exposure to the physical threats to human well-being and the capacity of people and communities to cope with those threats" [6]. Vulnerability is strongly linked to the complex make-up of society, including class, gender and age, past loss and misfortune, and susceptibility to future losses. Human vulnerability may be compounded by several factors [6]: (a) socio-economic status - position and status in society, which in turn are normally related to wealth, education and other conditions, such as type of housing which may be used as a proxy measure; (b) location - the geographical proximity to a hazard or potential hazard; (c) self-protection - the capacity to protect oneself from harm, including access to materials, knowledge, and information; and (d) social protection - the extent of assistance and support, including services, resources and technical expertise, that society can provide [2].

General health is an important determinant of livelihood and hence vulnerability and includes incidence and prevalence of diseases (specifically respiratory diseases and HIV/AIDS), nourishment, access to health care and life expectancy.

Absence of or inadequate supply of services may lead to personal exposure to several environmental health risks. Waterborne diseases, contaminated waste and indoor air pollution are the most common health hazards in low-income communities [6]. Therefore, three service factors include sanitation i.e. refuse disposal, energy use and main water supply.

Population demographics also provide an indication of the changing characteristics of a population. In South Africa, Statistics South Africa conducted a national survey of population demographics including average age, sex and household income in 1996 and 2001. Certain population demographics may be used to measure vulnerability to health hazards, specifically exposure to excess air pollution, since they have a direct or indirect influence on an individual's, household's or community's ability to cope. These demographics include enumeration area type, population density, age, sex, population group, and socio-economic status, incorporating highest education level, employment status and annual household income.

AQMPs identify several prioritised strategies and actions that must be implemented, but in their current form, these actions are prioritised independent of community vulnerability factors. This is seen as a major shortcoming, particularly in a country such as South Africa where funding and capacity are scarce. While ambient air pollution levels in excess of prescribed health standards are generally unacceptable, the exceedance is even more serious in areas where people reside. Such areas should be prioritised for action in the AQMP given the consequent detrimental acute and chronic health risks.

In a preliminary study, a population air pollution exposure and vulnerability risk assessment framework was derived [7]. A systematic approach was adopted 
and five themes identified, namely, (1) air pollution sources; (2) ambient air pollutant levels; (3) air pollution potential; (3) population vulnerability factors including population exposure; and (4) community awareness, perceptions, observations and actions. The main goals and specific indicators for each theme are provided in Table 1. The purpose of this framework was to assist air quality managers of local municipalities to identify at-risk communities in terms of air pollution exposure and vulnerability. In this way, informed decision-making for allocation of resources and service delivery to alleviate risk conditions and assist communities to better cope with their situations is possible.

Table 1: Five themes, their main goals and specific indicators for population air pollution exposure and vulnerability risk assessment [7].

\begin{tabular}{l}
\hline Theme and Main Goal \\
\hline Air pollution sources: To identify at-risk \\
communities based on proximity to air pollution \\
sources \\
Ambient air pollutant levels: To determine the \\
extent of the air pollution problem \\
Air pollution potential: To consider \\
environmental factors which may exacerbate \\
the problem \\
Population vulnerability factors: To consider \\
demographic factors which may affect a \\
community's ability to cope with exposure to \\
air pollution, and to identify especially \\
vulnerable communities and factors influencing \\
their vulnerability
\end{tabular}

awareness, perceptions, observations and actions: To include community complaints, media coverage, NGO activity

Note. ${ }^{*}$ Measured or modelled data where available. ${ }^{* *}$ Air pollutants identified from DEAT standards [8]. ${ }^{* * *}$ Proxy for domestic air pollution sources.

The proposed framework was developed through several iterations taking into account specific needs of the South African environment. It was applied to seven wards, four peri-urban and three urban wards, of the eThekwini Municipality (KwaZulu-Natal). Data were collected from multiple sources and collated. Results indicated that the four peri-urban wards being potentially at greater risk in terms of population vulnerability compared to the urban wards, although the range in scores was relatively small. The vulnerability indicators were then considered in the preparation of an air pollution M\&E framework for South Africa that takes into account air quality, health and most importantly, vulnerability. 


\section{Methods}

The proposed M\&E framework was derived through the review of several sources and informed by three main theories, i.e. Risk Assessment, Human Health Risk Assessment and DPSEEA (Driving force, Pressure, State, Exposure, Effects, Action) [9]. This is a framework developed by the World Health Organization (WHO) that brings together environment and health with actionbased outcomes at appropriate intervention levels. A set of indicators that assessed population health effects was developed, and used to appraise and quantify inequalities in exposures to air pollution and health effects to prioritise at-risk communities. These indicators were then considered for integration into an air pollution M\&E framework to assess mitigation measures specific to health outcomes in South Africa.

\section{Results and discussion}

The aim of an M\&E framework is to assess whether progress is being achieved in line with predetermined goals and objectives and to integrate data from different sources to determine whether goals are being met through comprehensive appraisal of short- and long-term impacts for recommendation design. An air pollution M\&E framework begins with establishment of air quality goals and standards then applies an inventory source and measures local air quality and meteorology to model air quality and implement legislation control to achieve ambient standards. Air quality measurement continues simultaneous to emission standards enforcement and the programme is evaluated and revised, where necessary, to achieve and maintain ambient air quality standards and goals. The largest challenge for an air pollution M\&E framework is deciphering impacts and indicators thereof, particularly related to health outcomes $[10,11]$ for the determination and evaluation of mitigation measures.

\subsection{Air pollution M\&E framework for health}

Air quality M\&E frameworks have been applied to air pollution abatement and control in several countries including Canada [12], Europe [13], Spain [14], and New Zealand [15]. Generally, air quality monitoring systems do not adequately address evaluation of population exposure to air pollution [13]. Moreover, implementation of health indicators have not played an integral role in the M\&E process, partly because there are no standardized, predefined environmental health indicators specific to air pollution. Using the DPSEEA approach, effects indicators related to air pollution should include, for example, mortality and morbidity in lung and heart disease; respiratory symptoms (especially in asthmatics and children under 5 years of age) and eye irritation [16]. However, previous M\&E frameworks have not focused on health outcomes when evaluating ambient air quality or mitigation measures. 


\subsection{Preliminary air pollution M\&E framework for South Africa}

In the 2007 National Framework for Air Quality Management [17], explicit detail is provided on air quality compliance monitoring, however, little mention is made regarding monitoring human health impacts. The ultimate aim of such compliance monitoring may be to alleviate excess air pollution exposure adverse health, however, community-specific health data are required and this is not mentioned in the National Framework.

Figure 1 outlines a preliminary air pollution M\&E framework for South Africa. A novel approach was adopted in defining the framework where health outcomes were prioritised as one of the key outcomes. The NEM AQA and the Draft Implementation Manual for Air Quality Management Planning [18] are the two key legislation requirements driving AQM in South Africa.

Based on these air pollutants and knowledge derived from health risk assessment, health indicators are identified and ambient air quality monitoring implemented concurrent to collection of data fulfilling the requirements of the tested vulnerability indicators provided in Table 2. Evaluation of results includes consideration of already-implemented mitigation measures and possible impacts, identification of additional air pollutants which may require monitoring based on results of specific health indicators, as well as alternative monitoring techniques best suited to monitor for health-outcomes based indicators.

In addition to monitoring of ambient air quality and meteorological factors, by following the steps laid out in Figure 1, air quality managers will be able to

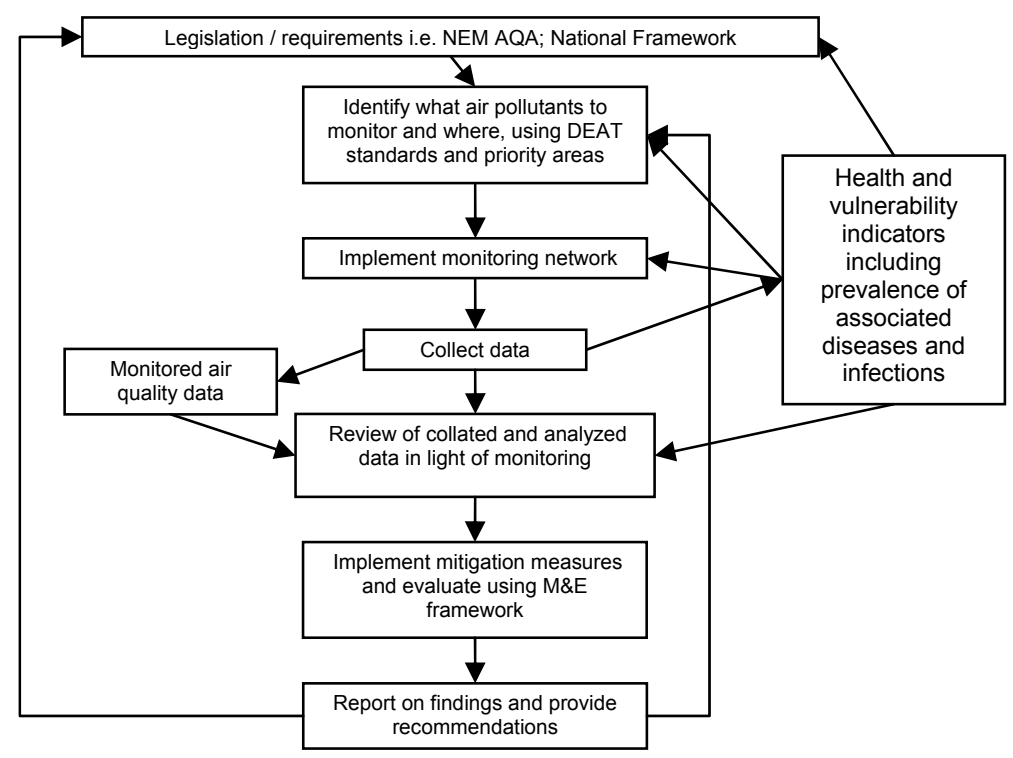

Figure 1: $\quad$ Proposed air pollution M\&E framework for South Africa. 
Table 2: $\quad$ Health and vulnerability indicators for air pollution M\&E [7].

\begin{tabular}{|c|c|c|c|}
\hline Measures & $\begin{array}{c}\text { High risk/ } \\
\text { most } \\
\text { vulnerable }\end{array}$ & Moderate risk & $\begin{array}{c}\text { Low risk/ } \\
\text { Least } \\
\text { vulnerable }\end{array}$ \\
\hline Average age of community members & $\begin{array}{c}<15 \text { and }>65 \\
\text { yrs }\end{array}$ & & $16-64$ yrs \\
\hline Number of female-headed households & $>65 \%$ females & $>50 \%$ females & $<50 \%$ females \\
\hline $\begin{array}{l}\text { Ratio of previously disadvantaged } \\
\text { groups to advantaged groups }\end{array}$ & $\begin{array}{l}>50 \% \text { Black, } \\
\text { African, } \\
\text { Coloured, } \\
\text { Indian or Asian }\end{array}$ & $\begin{array}{l}25-50 \% \text { Black, } \\
\text { African, } \\
\text { Coloured, } \\
\text { Indian or Asian }\end{array}$ & $>50 \%$ White \\
\hline $\begin{array}{l}\text { Prevalence of respiratory diseases } \\
\text { Prevalence of HIV/AIDS } \\
\text { Incidence of other communicable } \\
\text { diseases (i.e. TB, malaria, viral } \\
\text { hepatitis, typhoid, measles etc) }\end{array}$ & $\begin{array}{c}>45 \% \\
>45 \% \\
\text { High incidence }\end{array}$ & $\begin{array}{c}1-44 \% \\
1-44 \% \\
\text { Low incidence }\end{array}$ & $\begin{array}{l}0 \% \\
0 \% \\
\text { None }\end{array}$ \\
\hline Estimated life expectancy at birth & $<50$ yrs & $50-65 \mathrm{yrs}$ & $>65 \mathrm{yrs}$ \\
\hline $\begin{array}{l}\text { Number of doctors at local health } \\
\text { clinic and/or government hospital per } \\
1000 \text { people } \\
\text { Proximity to nearest clinic or } \\
\text { government hospital }\end{array}$ & $\begin{array}{c}<1 \\
>1 \mathrm{~km}\end{array}$ & & $\begin{array}{l}>1 \\
<1 \mathrm{~km}\end{array}$ \\
\hline $\begin{array}{l}\text { Proportion of children immunised } \\
\text { against diphtheria, pertussis, tetanus, } \\
\text { polio, hepatitis, TB and measles at age } \\
1 \mathrm{yr}\end{array}$ & $<20 \%$ & $20-80 \%$ & $>80 \%$ \\
\hline $\begin{array}{l}\text { Percentage of nutritional problems } \\
\text { recorded at nearest local health clinic } \\
\text { Proportion of schools providing } \\
\text { schoolchildren with food at school }\end{array}$ & $\begin{array}{l}>20 \% \\
<20 \%\end{array}$ & $\begin{array}{l}20-80 \% \\
20-80 \%\end{array}$ & $\begin{array}{l}<80 \% \\
>80 \%\end{array}$ \\
\hline $\begin{array}{l}\text { Specialist study (exposure and activity } \\
\text { patterns) completed and presence of } \\
\text { risk found }\end{array}$ & Risk evident & No risk evident & No risk evident \\
\hline Frequency of waste removal & No removal & $\begin{array}{l}\text { Less than } \\
\text { weekly }\end{array}$ & $\begin{array}{c}\text { Once/twice a } \\
\text { week }\end{array}$ \\
\hline \begin{tabular}{lll|}
$\begin{array}{l}\text { Proportion of } \\
\text { paraffin and gas }\end{array}$ & community & using \\
\end{tabular} & $>80 \%$ & $20-80 \%$ & $<20 \%$ \\
\hline $\begin{array}{l}\text { Proportion of community using } \\
\text { untreated water } \\
\text { Proportion of community having a } \\
\text { shared water supply greater than } \\
200 \mathrm{~m} \text { away }\end{array}$ & $\begin{array}{l}>80 \% \\
>80 \%\end{array}$ & $\begin{array}{l}20-80 \% \\
20-80 \%\end{array}$ & $\begin{array}{l}<20 \% \\
<20 \%\end{array}$ \\
\hline $\begin{array}{l}\text { Proportion of community having none } \\
\text { or any type of toilet other than a flush } \\
\text { toilet }\end{array}$ & $>80 \%$ & $20-80 \%$ & $<20 \%$ \\
\hline $\begin{array}{l}\text { Proportion of informal and tribal } \\
\text { settlements }\end{array}$ & $>80 \%$ & $20-80 \%$ & $<20 \%$ \\
\hline Number of people per $\mathrm{km}^{2}$ & $>500 \mathrm{~km}^{2}$ & & \\
\hline $\begin{array}{l}\text { Proportion of community achieving } \\
\text { Grade } 12 \text { (of potential age) and higher }\end{array}$ & $<20 \%$ & $20-80 \%$ & $>80 \%$ \\
\hline $\begin{array}{l}\text { Proportion of community } \\
\text { unemployed, scholar or student, } \\
\text { home-maker or housewife, pensioner } \\
\text { or retired person/to old to work, } \\
\text { unable to work due to illness or } \\
\text { disability, seasonal worker not }\end{array}$ & $>80 \%$ & $20-80 \%$ & $<20 \%$ \\
\hline
\end{tabular}


Table 2: $\quad$ Continued.

\begin{tabular}{|c|c|c|c|}
\hline Measures & $\begin{array}{c}\text { High risk/ } \\
\text { most } \\
\text { vulnerable }\end{array}$ & Moderate risk & $\begin{array}{l}\text { Low risk/ } \\
\text { Least } \\
\text { vulnerable }\end{array}$ \\
\hline $\begin{array}{l}\text { working presently, does not choose to } \\
\text { work, or could not find work }\end{array}$ & $>80 \%$ & $20-80 \%$ & $<20 \%$ \\
\hline $\begin{array}{l}\text { Annual average household income } \\
\text { (R430/month) }\end{array}$ & $<$ R5 160 & $\begin{array}{l}\text { R5 160-R10 } \\
000\end{array}$ & $>$ R10 000 \\
\hline $\begin{array}{l}\text { Recent disasters (i.e. floods, fires } \\
\text { from tank explosions, toxic waste } \\
\text { spills) }\end{array}$ & $\geq 1$ & 0 & 0 \\
\hline $\begin{array}{l}\text { Number of crimes reported per annum } \\
\text { per } 100000 \text { people (in a South } \\
\text { African community) }\end{array}$ & $>4500$ & $2500-4500$ & $<2500$ \\
\hline $\begin{array}{l}\text { Area per capita of community } \\
\text { designated public parks, gardens and } \\
\text { other open space for potential mental } \\
\text { health benefits }\end{array}$ & $<1 \mathrm{~km}^{2}$ & & $>1 \mathrm{~km}^{2}$ \\
\hline
\end{tabular}

effectively implement monitoring programmes and mitigation measures bearing in mind the endpoints, namely health outcomes, throughout the entire process. Special attention should be paid to Priority Areas or 'hotspots' defined as an area declared as such under section 18 of NEM AQA. Here, population exposure must be evaluated, at least in terms of type of indoor fuel use as a proxy for air pollution exposure. Future research is needed to trial and implement improved and validated techniques for personal air pollution exposure measurements, especially for $\mathrm{SO}_{2}$ and $\mathrm{PM}_{10}$.

\section{Conclusion}

In their current form, activities in South African AQMPs do not incorporate whether proposed enforced compliance of air pollution emitting activities and associated mitigation measures will be evaluated in terms of health outcomes. The implementation of an air pollution M\&E framework with specific focus to include consideration of health and vulnerability ensures that efforts consuming time, money and human capacity will not continue without appropriate assessment. More specifically, the benefits of a South African-applied air pollution M\&E framework include implementation of environmental health indicators to assess mitigation efficiency and efficacy; motivation for provision of rigorous, up-to-date health data at appropriate resolutions and; provision of health-oriented direction for air quality managers.

\section{Acknowledgements}

Financial support for this research project was provided by a Young Researcher Establishment Fund grant administered by the Council for Scientific and Industrial Research (CSIR). 


\section{References}

[1] Brunekreef, B. \& Holgate, S. Air pollution and health. Lancet 360:1233-12, 2002.

[2] Makri, A. \& Stilianakis, N.I., Vulnerability to air pollution health effects. Int J Hyg Environ- Health, 211:326-336, 2008.

[3] DEAT, National Environmental Management: Air Quality Act No. 39 of 2004, 2004.

[4] Department of Health, South Africa Demographic and Health Survey Full Report. Pretoria, South Africa, 1-338, 1998.

[5] MRC, Risk factors South African Comparative Risk Assessment Summary Report January 2008. Pretoria, South Africa, 1-19, 2008.

[6] DEAT, South Africa Environment Outlook. DEAT, Pretoria, South Africa, 2006.

[7] Wright, C. \& Diab, R. Air pollution and vulnerability" solving the puzzle of prioritization, in press, 2009

[8] DEAT, The identification of substances in ambient air and establishment of national standards for the permissible amount or concentration of each substance in ambient air. Government Gazette No. 31987, 13 March 2009. DEAT, Pretoria, South Africa, 2009.

[9] Corvalan C., Briggs D. \& Kjellstrom T. Development of environmental health indicators. In: Linkage Methods for Environment and Health Analysis: General Guidelines. A Report of the Health and Environment Analysis for Decision-making Project. UNEP, US EPA, WHO (Briggs D, Corvalan C, Nurminen M, eds). Geneva: Office of Global and Integrated Environmental Health, World Health Organization, 19-53, 1996.

[10] Ministry for the Environment, Preliminary assessment of potential human health indicators of air quality. Prepared for the Ministry for the Environment Environmental Performance Indicators Programme, Wellington, June 1999: 1-30, 1999.

[11] Ministry for the Environment, Good-practice guide for air quality monitoring and data management. Wellington, December 2000: 1-111, 2000.

[12] Huyn Shin, H., Burnett, R.T., Steib, D.M., \& Jessiman, B. Measuring public health accountability of air quality management, Air Qual Atmos Health, 2:11-20, 2009.

[13] Mucke, H.-G., Ambient air quality programmes for health impact assessment in the WHO European region, Arh Hig Rada Toksikol, 51:257$564,2000$.

[14] Ferreira, F., Tente, H., Torres, P., Cardoso, S., and Palma-Oliveira, J.M. Air Quality Monitoring and Management in Lisbon. Env Monitor Assessment 65:443-450, 2000.

[15] Kjellstrom, T., Preliminary Assessment of Potential Human Health Indicators of Air Quality, Prepared for the Environmental Performance Indicators Programme of the Ministry for the Environment, June 1999, 130, 1999. 
64 Environmental Health Risk V

[16] WHO, Environmental Health Indicators: Framework and Methodologies, WHO/SDE/OEH/99.10, 1-122, 1999.

[17] DEAT, National Framework for Air Quality Management in the Republic of South Africa, 2007.

[18] DEAT, Draft Implementation Manual for Air Quality Management Planning as contemplated in Sections 15-17 of the National Environmental Management: Air Quality Act No. 29 of 2004. 